\title{
Granule and Solvent for Oral Suspension Dosage Form
}

National Cancer Institute

\section{Source}

National Cancer Institute. Granule and Solvent for Oral Suspension Dosage Form. NCI

Thesaurus. Code C149544.

Granules and solvent intended for the preparation of an oral suspension by dispersing the granules in the solvent. 